\title{
1967-77: Ten years of marine geology and geophysics
}

\section{Xavier Le Pichon}

\author{
CNEXO, B.P. 107, Paris 75116 and COB, B.P. 337, 29273 Brest, France
}

- Plate tectonics gave a great stimulus to marine geology and geophysics; in the years since its enunciation there have been major drilling programmes, a new science of global palaeoenvironmental oceanography and much more detailed oceanographic surveys. The pace shows no sign of slackening-in the next few years the passive continental margins will be much studied.-

IN April 1967, Jason Morgan ${ }^{1}$, having unexpectedly changed the subject of his talk, demonstrated to a large audience at the American Geophysical Union meeting, in Washington, how sea-floor spreading in the Atlantic Ocean had occurred between two rigid 'crustal blocks' moving apart on the surface of the spherical earth. This 'plate tectonics' model of the Earth's surface was implicit in the sea-floor spreading hypothesis of $\mathrm{Hess}^{2}$, with its two corollaries of Vine and Matthews ${ }^{3}$ magnetic lineations and Tuzo Wilson ${ }^{4}$ transform faulting. But although the magnetic anomaly profiles across the East Pacific rise had convinced many earth scientists by early 1966 of the reality of sea-floor spreading, the demonstration made by Morgan was largely ignored by the audience. It is only during the following years that the full impact of rigid plate kinematics led to the present revolution in the Earth sciences. And this revolution has been most spectacular in marine geology and geophysics, which, with earthquake seismology, furnished most of the discoveries on which it is based.

It is in the field of global kinematics, past and present, that the progress has been most rapid. Because plates are rigid, it has been possible to construct a fairly precise global quantitative model for the present interaction of the 11-12 major plates, along their boundaries which are generally covered by several kilometers of water. In addition, it has been possible to decipher, at least in a preliminary way, the complex kinematic history of all large oceans, through the powerful Vine and Matthews method of dating the igneous oceanic crust. Thus, for the first time, there is a successful quantitative model of the dynamic evolution of the earth surface, a model which has been repeatedly tested, in particular through the use of deep-ocean drilling.

\section{Deep-sea drilling}

In 1968, at the time when the plate tectonics model was being accepted by the scientific community as the working model, the D. V. Glomar Challenger set out to drill her first hole through the floor of the Gulf of Mexico. She is now drilling her 418 th hole and the results ${ }^{3}$ obtained by the Deep Sea Drilling Program (DSDP), under the sponsorship of JOIDES (Joint Oceanographic Institutions for Deep Earth Sampling) have shown that the proposed kinematic evolution of the oceans is supported by the analysis of the sedimentary column and the underlying igneous crust. In particular, the magnetic reversals absolute timescale, which is the basic tool to unravel the history of the oceans and which is now known from present to Middle Jurassic (165 Myr ago) with a relatively good precision ( $\approx 10 \mathrm{Myr}$ ), was entirely calibrated by deep-sea drilling results.
The single most important accomplishment of deep sea drilling, however, was the creation in the last 3-4 yr of a new field of science-global palaeoenvironmental oceanography. This occurred as it was progressively realised that the drastic changes in the Earth surface configuration are highly correlated to changes affecting the hydrosphere and the atmosphere, but also the biosphere. It now seems possible to obtain reasonable physical models which broadly account for the deterioration of climate during the last $40 \mathrm{Myr}$, simply by taking into account the different oceancontinent distribution pattern (for example, ref. 6).

\section{Palaeoenvironmental oceanography}

In the last $200 \mathrm{Myr}$ the Earth surface configuration has changed from a supercontinent, Pangea, surrounded by a proto-Pacific super-ocean, Panthalassa, to the present fragmented ocean and dispersed continents. Panthalassa had a western prolongation, called Thetys, inserted like a wedge between Eurasia to the north, and Africa, India and Australia to the south. Its margin was almost entirely a consuming plate boundary where oceanic lithosphere was being subducted under the continent. Very little is known about its palaeo-oceanography as most, if not all, of the Triassic $(\sim 200 \mathrm{Myr})$ lithosphere has since returned into the mantle. Future drilling may, however, obtain Lower Jurassic sediments from the oldest portion of the Pacific ocean, which is now in the process of disappearing along the western consuming plate boundary, thus providing essential data on Panthalassa.

There is much better information on the evolution of the world ocean during Mesozoic, 165-60 Myr ago, which was characterised by ocean basins in an early stage of evolution, the newly born Atlantic and Indian basins, by a mature but shrinking proto-Pacific and a disappearing Tethys. The breaking up of Pangea resulted in the creation of rifted inactive margins where a great proportion of the Earth's sediments have now been trapped, bordering shallow $(\approx 3 \mathrm{~km})$ and narrow basins underlain by hot oceanic lithosphere. The ocean environment under an equable climate, was fairly tranquil with thermo-haline homogeneity and mostly latitudinal, probably wind-controlled circulation pattern (for example, ref. 7).

The new ocean basins continuously widened but also deepened, as they became older. The relationship between ocean-depth and age of the plate is a direct consequence of the lithospheric plate being a thermal boundary layer which moves away from its zone of creation at the axis of the mid-ocean ridge. It is a powerful tool to reconstruct the palaeobathymetry of a given ocean, knowing its age.

This age-depth relationship also implies that the average depth of the world ocean is related to its average age. Thus a faster rate of lithosphere renewal should lead to overflow over the continental borderlands, and vice versa. This effect may be the principal cause of the worldwide transgressions and regressions, outside of the geologically relatively recent changes in the volume of the ice-caps. The well known Upper Cretaceous ( $80 \mathrm{Myr}$ ago) transgression, during which $85 \%$ of the Earth was covered by water (compared with $71 \%$ today and $65 \%$ during the largest regressions), has been explained in this way ${ }^{3}$. In any case, 

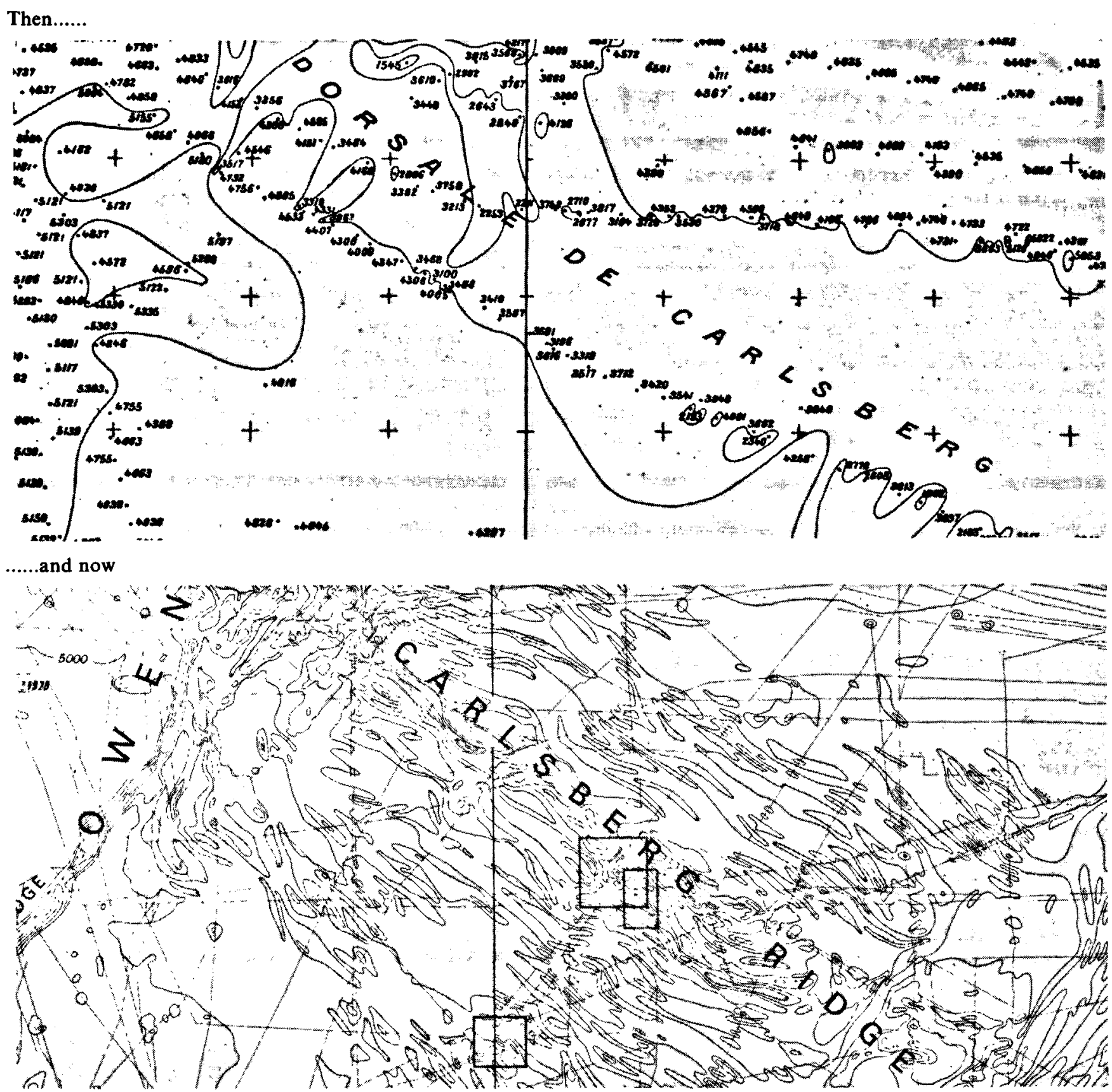

A General Bathymetric Chart of the Oceans was first published in 1903 by Prince Albert of Monaco. The upper picture shows a portion of the 1938 edition for the Indian Ocean just east of Somalia $(1.400 \times 900 \mathrm{~km})$. This chart was still in use at the beginning of the International Indian Ocean Expedition in 1959. The 1975 edition (lower) shows the same area as now charted. The Carlsberg Ridge is now seen to run into the Owen Fracture Zone. Contours are at 1,000 m spacings; ship's tracks are marked lightly.

recent oceanographic, mostly oil-applied research, has demonstrated the existence on the continental margins of numerous global unconformities which are related to sealevel changes. It now seems possible to reconstruct a fairly precise history of the evolution of sea level during the last $200 \mathrm{Myr}$.

The radical change brought by the Cainozoic ( $<60 \mathrm{Myr}$ ) era, which transformed the warm ocean and mild climates of the Mesozoic into the cold ocean and glacial climates of the Quaternary $(<3 \mathrm{Myr})$ has been described as a 'commotion in the ocean". The most dramatic change occurred $38 \mathrm{Myr}$ ago with a drop of about $10^{\circ} \mathrm{C}$ of the deep water temperature ${ }^{\theta}$. This was related to the formation of a circumantarctic seaway, with separation of Australia from Antarctica and the opening of the Drake passage, and to the closure of the Tethys. Strong thermo-haline deep circulation became well developed, resulting in widespread sea-floor erosion and the present meridional as well as latitudinal circulation pattern was established at this time.

But, it is still not understood why, whereas the first seaice appeared $38 \mathrm{Myr}$ ago, the Antarctic ice-sheet did not develop for another $20 \mathrm{Myr}$. As for the Arctic ice-sheet, it started to develop $3 \mathrm{Myr}$ ago and this event may be related to the creation of the Central America land bridge. The history of the repeated Late Pliocene-Pleistocene $(<3 \mathrm{Myr})$ southward transgression of polar water by as much as $20^{\circ}$ of latitude is now being very precisely reconstructed. One can expect in the years to come major progress in the understanding of this Cainozoic 'commotion' from such ocean sediment studies and from oceanologic and climatic modelling.

\section{Geochemistry and geology}

The role of the world ocean as a geochemical sink is also being progressively revealed. The degree of oxygenation of the deep ocean has greatly changed. It seems to have been 


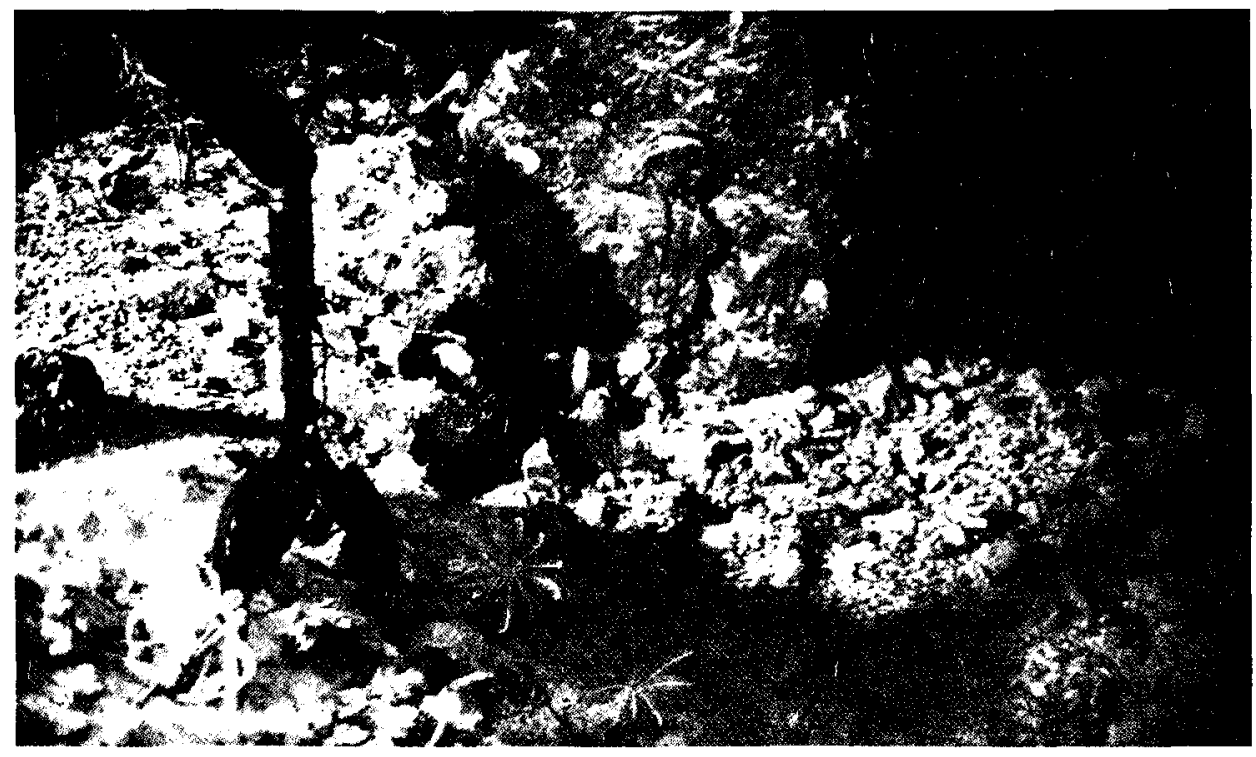

Mechanical arm of CNEXO submersible CYANA sampling a piece of pillow at $2,700 \mathrm{~m}$ depth in Transform Fault $\mathrm{A}$ in the Atlantic Ocean during the FAMOUS project. Part of a vertical dyke is seen in the background and numerous signs of animal life.

mostly poorly oxygenated during Mesozoic whereas it is highly oxygenated nowadays. These changes probably deeply affected the carbon cycle in the hydrosphere and the carbon dioxide contents of the atmosphere. The development of calcareous and siliceous microorganisms during the Mesozoic must also have introduced a basic change in this geochemical complex cycle.

In contrast, there has been relatively little progress in our understanding of the geological structures generated or modified by the processes of plate tectonics, and first the oceanic lithosphere itself. A striking example concerns its upper portion: the oceanic crust. We know its age nearly everywhere but we still do not know unambiguously its structure and composition. Fifteen years ago, marine geophysicists had proposed, on the basis of seismic refraction results, that the oceanic crust had a homogeneous and uniform three-layer stratification (1, sediments; 2 , basement; 3 , 'oceanic layer') on top of the upper mantle. Layer 2 was supposed to be made of basalt and layer 3 of gabbro. Hess later proposed that layer 3 consisted instead of serpentinised peridotite. Today, the controversy is still not resolved. The oceanic crust models proposed nowadays are partly based on the results of scattered, poorly located dredgings out of a precise structural frame work but they mostly draw on analogies with ophiolites and predictions based on highly simplified theoretical models.

To this day, drilling has failed to shed much light on this problem because of technological limitations. The largest penetration in the igneous crust does not exceed $600 \mathrm{~m}$, that is about one tenth of the thickness of the crust. In addition, the necessity to dispose of a least $100 \mathrm{~m}$ of sediments over the igneous crust to stabilise the drill bit excludes most of the actively accreting boundaries from being sampled. Consequently, no direot information can be obtained on the actual processes of formation of the crust by drilling. It is fair to conclude that our poor knowledge of the oceanic crust results from the scarcity of direct geological evidence.

An important development, in this domain, has been the introduction of a much more refined seismic refraction investigation of the ocean crust and lithosphere, with ocean bottom seismographs (the so-called OBS) and better inversion techniques. The resulting acoustic structure is apparently quite complex and variable, as would be expected. Layer 2 seems to be a zone of strong velocity gradient with an uppermost very low velocity zone which progressively disappears with age. There is no generally accepted standard structure for layer 3 and its evolution with age, although it has recently been proposed that a rapid thickening away from the rise crest is due to the formation of a low velocity zone at its base. There is some fairly strong evidence for the existence of a magma chamber at a depth of $2 \mathrm{~km}$ below the sea floor under the East Pacific rise ${ }^{10}$. No such magma chamber could be detected under the crest of the slower spreading mid-Atlantic ridge.

Very long seismic refraction lines and earthquake seismological studies (primarily surface waves) have given some important information on the structure and evolution of the lithosphere with age. If the thickness of the lithosphere is defined by the lid of the underlying low velocity zone, there is a definite thickening with age from less than $50 \mathrm{~km}$ to $80-90 \mathrm{~km}$. In the accretion zone, under the crest of the mid-ocean ridge, where the lithosphere is being created, a zone of partial melting comes within a small distance from the sea floor. Strong internal stratification seems to be common within the lithosphere.

Although this whole field of direct modern investigation of the structure and evolution of the crust and lithosphere by explosion and earthquake seismology is very promising, it is still in its infancy and it is too early to make firm conclusions. Note that an interesting new technique may well be the use of commercial multi-channel seismic reflection for recording oblique reflections from the crust and mantle. Another important new technique will certainly be the use of seismic receivers in the deep-sea drilled holes.

In the absence of detailed direct measurements, physical models based on plate tectonic concepts could bridge the gap in our knowledge. It is true that it is relatively easy to explain heat flow and water depth variation as a function of age (see ref. 11, for example). But, this success does not mean that the formation of the oceanic crust and lithosphere is understood. Most of the proposed models are purely thermal and ignore the mechanical definition of the lithosphere. Further, widely different sets of parameters can be chosen, provided that the principle of a rigid thermal boundary layer is preserved. And, most important, their results away from the axis do not depend on the mode of transfer of material from the asthenosphere to the lithosphere in the rather narrow accreting zone. Yet, the knowledge of this mode of transfer is essential to any modellisation of the formation of the lithosphere and crust. Clearly, additional constraints are needed. An interesting new one has recently been shown to be that the ocean depth does not increase as fast beyond $60-80 \mathrm{Myr}$ as would be required if it were the cooling of a thermal boundary layer, which indicates the existence of additional sources of heat.

Thus, our knowledge of the ocean crust and lithosphere. 
structure is still schematic. Is there a clearer understanding of the geological structures created by the interaction of plates along their boundaries? In fact, most of the geological models proposed for a consuming plate boundary (deep-sea trench), for an accreting plate boundary (spreading centre), or for a transform boundary are in great part hypothetical and grossly simplified.

Yet, approximately $120,000 \mathrm{~km}$ of length of plate boundaries lie below $2.5-11 \mathrm{~km}$ of water, which have no equivalent or directly comparable tectonic features above sea level. This is about $80 \%$ of the total length of the boundaries of the well defined plates. It is along the oceanic accreting boundaries that the tectonic fabric of the ocean floor is created. It is along the oceanic consuming boundaries that some of the tectonic fabric of the future subaerial mountain belts is presumably set into place. An understanding of the process of formation of the oceanic crust requires knowledge of the spatial and temporal distribution of the volcanic and tectonic events leading in turn to a full comprehension of the pattern of geochemical variation within the accreting plate boundary area. An understanding of the process of subduction also requires a knowledge of the spatial and temporal distribution of the tectonic features within the consuming plate boundary area and this, in turn, can lead to important information on the rheology of the plate itself. Clearly, any coherent development of the plate tectonic model passes by an adequate study of these boundaries.

\section{FAMOUS}

Standard oceanographic techniques currently used by most investigators are not adequate for this type of detailed geological and geophysical surveys as they have a spatial resolution which is not much better than half of the water depth. As a result, so-called detailed surveys of ten have a grid spacing of $10 \mathrm{~km}$ or more. Yet, studies of magnetic anomalies using precisely navigated deep-tow studies, have shown that the width of the zone of creation of oceanic crust in accreting plate boundaries is $2-6 \mathrm{~km}$. To resolve processes occurring on such a scale, one needs to use techniques having a much better resolution with very precise navigation. These techniques should of course include bathymetry, seismic refraction survey and detailed geological surface mapping with precisely located multiple drillings. Such a complete study has not yet been performed. The FAMOUS program has made an important step in this direction ${ }^{12-13}$, however.

The French American Mid-Ocean Undersea Study (FAMOUS) was designed 'to conduct an integrated and detailed geological, geophysical and geochemical study of a portion of plate boundary where new oceanic crust is generated' in the North mid-Atlantic ridge. The main characteristic of this study is that, for the first time in deep ocean, object having a size from a few centimetres to kilometres were mapped and placed within the framework of a precise structural context. This was done in a first phase with the help of precisely navigated surface ship studies using the powerful multi-narrow beam echo-sounder, deeptow fish and transponder located dredges and bottom photographs. Then, in a second phase, precisely navigated manned research submersibles established well documented geological sections, with both tectonic observations and rock sampling. Thus, methods of classical field geology could be applied to the deep ocean floor. As a result, a precise structural and petrological model of the Rift Valley and intersecting transform fault has been obtained for the first time.

But FAMOUS was just a beginning. There is little doubt that future research will rely more and more on studies with the same amount of resolving power, from seismic refraction to field geology. A good example is the problem of hydrothermal circulation in newly formed oceanic crust which has been shown to have a major role in the cooling of the crust, the distribution of heat flow, the formation of mineral deposits leached from the crust and the general geochemical cycle of seawater. The vents through which hot water comes to the sea-floor have such a small size that they require high-resolution techniques to be studied. The research submersible Alvin is now making such a study on the Galapagos rise, in the Eastern Equatorial Pacific ocean.

Perhaps, because of the formidable depths at which they lie, consuming plate boundaries have been studied in less detail $^{14}$. However, a great step forward in their exploration was made with the acquisition of good commercial seismic reflexion lines revealing the structure of the inner wall which actually consists of a sedimentary accretionary wedge, made of imbricated thrust sheets which is several tens of kilometres long and up to tens of kilometres thick. The actual process of formation of this complex wedge is still not well understood and may include alternating phases of erosion and accretion. It has even been proposed that considerable erosion of continental crust may occur. The importance of such processes in an understanding of the geodynamics cannot be over emphasised.

\section{The future}

The next $2 \mathrm{yr}$, which will see the first systematic attempts at drilling consuming plate boundaries, should shed considerable light on these problems. But a much greater effort is needed to resolve their detailed structure and tectonics. For example, the detailed pattern of microseismicity across a trench is still essentially unknown, although a few OBS measurements have been made.

It is quite probable, however, that, in the next 4-5 yr, the greatest effort of the marine geoscience community will go towards solving the structure and evolution of passive continental margins which contain, as mentioned above, up to $50 \%$ of all the Earth's sediments. In addition to their potential economic interest, the passive continental margins are probably the only places where one can find the record of the early stages in the formation of a new ocean. There is still considerable disagreement on such fundamental problems as the nature of the continental crust-ocean crust transition, the actual boundary of the original continent, the processes which have allowed the thinning of the continental crust and the relative importance of the possible processes of subsidence. The ultimate tool for this type of investigation, very deep drilling, is actually being actively considered in spite of the very large costs involved.

For this review to have been truly complete, many other results as well as planned investigations would have had to be mentioned. In addition, no single writer can possibly cover adequately such a large field, so this review is certainly somewhat biased. There is, however, little doubt that the large scale exploration phase of the world ocean made in the framework of plate tectonics in the last $10 \mathrm{yr}$ is now coming to an end. The next phase will require much more elaborate, more costly techniques, having a greater resolving power to lead to a correct modellisation of the various physical and chemical processes involved in the functioning of the great lithosphere engine.

\footnotetext{
1 Morgan, W. J. J. geophys. Res. 73, 1959-1982, 1968.

Hess H. H. in Petrologic studies-Buddington Memorial vol. Geol. Soc. Am. New York, N.Y., 599-6620 (1962).

3 Vine, F. J. \& Matthews, D. H. Vature 199, 947-949 (1963).

4 Wilson, J. T. Vature 207, 343-347 (1965).

5 Intial Reports Deep Sea Drilling Project I-XXXVII, (US Government Printing Office, Washıngton, 19691977 .

6 Donn, W. L.. \& Shaw, D. M. Bull.geol. Soc. Am. 88, 390-396 (1977)

7 Berggren, W. A. \& Hollister, C. D. Tectonophusics 38, $11-48$ (1977)

8 Hay, J. D. \& Pitman, W. C. Vature 246, 18-22(1973)

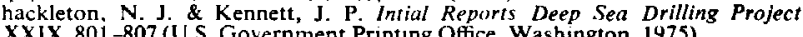
XXIX, 801-807 (U.S. Government Printing Office, Washington, 1975).

11 Sosendahl, B. R. J. geophys, Re , 81, 5300-5314, 1976.

12 Arcyana, X. Y. Science 190, 108 . 116 (1975).

13 Ballard, it. D. et al. Sience 190, 103-108 (1975). Burk, C. A. \& Drake, C. L. The Geology of Continental Margins, (Springer, New
York, 1974).
} 